ALTERIDADES, 2018, 28 (55): Págs. 25-36

https:www.doi.org/ 10.24275/uam/izt/dcsh/alteridades/2018v28n55/Aragon

\title{
Las revoluciones de los derechos indígenas en Michoacán Una lectura desde la lucha de Cherán*
}

\author{
ORLANDO ARAGÓN ANDRADE**
}

\begin{abstract}
The Revolutions of the Indigenous Rights in Michoacán. A READING OF THE BATtLE OF CHERÁn. This paper intends to explain the logic of the strong growth of judicial precedents and legislative innovations of crucial importance for indigenous peoples in Mexico, that have taken place during the last six years in Michoacán. The starting point of this investigation is the beginning of the Purépecha movement, in Cherán. This process, which we refer to as the revolution of indigenous rights in Michoacán, has emerged in a new scenario marked by its heterogeneous nature and the schizophrenia of the State law, as well as an exaggeration of the right of free determination by Purépecha movements in Cherán and Pichátaro.
\end{abstract}

Key words: free determination of indigenous peoples, legal pluralism, legal schizophrenia, political-legal alchemy, Pichátaro

\begin{abstract}
Resumen
Busco explicar la lógica del desarrollo explosivo de precedentes judiciales e innovaciones legislativas de primer orden de importancia para los pueblos indígenas de México, que se han producido en los últimos seis años en Michoacán. Parto de la investigación militante que vengo realizando desde el inicio del movimiento purépecha de Cherán. Sostengo que este proceso, que denomino la revolución de los derechos indígenas en Michoacán, se ha generado en un nuevo escenario marcado por la heterogeneidad y esquizofrenia del derecho estatal, y el desbordamiento del derecho de libre determinación por los movimientos purépechas de Cherán y Pichátaro.
\end{abstract}

Palabras clave: libre determinación de los pueblos indígenas, pluralismo jurídico, esquizofrenia legal, alquimia política-jurídica, Pichátaro

\section{Introducción}

$\mathrm{D}$ urante mucho tiempo Michoacán, a pesar de las importantes movilizaciones que protagonizaron organizaciones indígenas en las últimas décadas del siglo xx, se destacó por ser una de las entidades federativas con una legislación en derechos de los pueblos indígenas más retrógrada (Ventura Patiño, 2010; Aragón Andrade y Montero Tapia, 2008). En efecto, a diferencia de lo ocurrido en otros estados con presencia indígena que experimentaron un desarrollo importante en sus leyes en materia de derechos de los pueblos indígenas durante la primera década de este siglo, Michoacán continuó con un marco constitucional previo al del artículo $2^{\circ}$ de la carta magna federal y con apenas una ley secundaria sobre la materia.

\footnotetext{
* Artículo recibido el 20/07/17 y aceptado el 03/10/17. Este trabajo fue realizado con el apoyo del proyecto PAPIIT IA303516 otorgado por la Universidad Nacional Autónoma de México.

** Escuela Nacional de Estudios Superiores-Morelia de la Universidad Nacional Autónoma de México. Antigua carretera a Pátzcuaro núm. 8701, col. Exhacienda de San José de la Huerta, 58190, Morelia, Michoacán <orlandoarande@yahoo. com.mx>.
} 
Esta realidad jurídica de los pueblos indígenas en Michoacán encontró un punto de inflexión en 2011 , particularmente con el surgimiento del Movimiento por la Seguridad, la Defensa del Bosque y la Reconstitución del Territorio, de la comunidad purépecha de San Francisco Cherán. A partir de la judicialización de sus demandas para tener una elección y un gobierno municipal por usos y costumbres y de su triunfo en el Tribunal Electoral del Poder Judicial de la Federación (TEPJF) se abrió una nueva etapa, que aquí llamo la revolución de los derechos indígenas, ${ }^{1}$ en la cual en tan sólo seis años se han producido dos reformas constitucionales en la materia, dos adecuaciones en legislaciones secundarias que colocan a Michoacán a la vanguardia en algunos de estos derechos y tres de los precedentes judiciales más significativos en relación con el derecho a la libre determinación en todo México.

Sin embargo, para varios estudiosos este significativo desarrollo de los derechos indígenas en $\mathrm{Mi}$ choacán ha ocurrido de manera desordenada y caótica, al grado de que ha quedado en entredicho la ruta que está siguiendo. Justamente éstos son los puntos abordados en este trabajo. Mi análisis parte desde mi posición de integrante del Colectivo Emancipaciones, el grupo de abogados que ha acompañado la lucha de la libre determinación de Cherán a partir de 2011 , y desde la investigación militante que ahí realizo desde hace más de seis años.

Son dos los objetivos generales que me propongo conseguir en esta contribución. Primero intento mostrar la coherencia y lógica que ha seguido la revolución de los derechos indígenas en Michoacán, cuestionando las perspectivas dominantes de análisis legal que descansan en miradas desde el Estado o desde arriba. En segundo término pretendo explicar las contribuciones más importantes de los avances legislativos y judiciales ocurridos en esta revolución de los derechos indígenas, dando un contexto de las circunstancias en las que fueron producidas cada una de ellas.

La ruta que sigo para alcanzar estos dos puntos comienza con una reflexión sobre la apropiación y desbordamiento del derecho de libre determinación que han realizado las comunidades purépechas desde 2011. En un segundo momento discuto algunos cambios significativos que han sufrido en las últimas décadas el derecho estatal y sus instituciones en México que ayudan a entender el surgimiento de esta revolución de los derechos indígenas en Michoacán. En tercer lugar me concentro en estudiar los tres precedentes judiciales de primer orden nacional producidos en Michoacán en el ámbito del derecho a la libre determinación de los pueblos y comunidades indígenas. El análisis de las innovaciones en el campo legislativo me ocupa en una cuarta instancia, y cierro este trabajo con un conjunto de reflexiones finales.

\section{El derecho a la libre determinación de los pueblos y comunidades indígenas desde abajo}

Como ha advertido Balakrishnan Rajagopal (2005), una de las cosas que parecen más distantes de la gente común es el derecho internacional de los derechos humanos. Éste parece ser producto de la filantropía de los organismos internacionales y de las organizaciones transnacionales de derechos humanos, o de disquisiciones realizadas por tribunales internacionales tan lejanas de las personas de a pie, que en el mejor de los casos acceden a ellos mediante un proceso de vernacularización (Merry, 2010).

Esta forma en la que efectivamente los estudios jurídicos y sociojurídicos han analizado la producción del derecho internacional de los derechos humanos ha coincidido y ensamblado con el procedimiento jurídico de legibilidad (Scott, 1998) estatal más tradicional. Ciertamente, la lógica de ordenación del derecho estatal es imponer una construcción jurídica desde arriba que dé sentido y simplifique la realidad social. La mejor ilustración de este presupuesto son quizás las implicaciones que supone la relación entre el derecho constitucional y sus normas. La lógica de esta rama del derecho estatal descansa sobre la suposición de que todas las normas secundarias derivan y por lo tanto están en consonancia con la constitución.

\footnotetext{
1 La expresión de la revolución de los derechos indígenas que da título a este trabajo hace un claro guiño a la investigación clásica de Charles Epp (2013). Sin embargo, debo aclarar que no baso mi análisis en su propuesta teórica, porque pienso que, aunque comparte elementos comunes con el contexto mexicano y michoacano que estudio, muchos otros difieren abiertamente. Por ejemplo, varios de los elementos de la "estructura sostén" que Epp consideró fundamentales para la revolución de los derechos en Estados Unidos para nada están presentes en el contexto aquí analizado, tal es el caso de organizaciones, abogados especialistas y mucho menos financiación desde el gobierno para la defensa de estos derechos. También es importante advertir que en esta contribución me refiero como revolución de los derechos indígenas únicamente a los derechos de los pueblos y comunidades indígenas reconocidos o bien en sede judicial o en la legislación estatal. De tal manera, las justicias indígenas de las comunidades de Michoacán no forman parte del análisis que en este trabajo se propone.
} 
Incluso, el discurso jurídico posmoderno de aplicación de tratados internacionales de derechos humanos en el derecho nacional conserva esta lógica, y refuerza la idea de que todo el derecho estatal debe estar en consonancia con el derecho internacional de los derechos humanos o bien con el derecho constitucional.

Justamente por seguir esta lógica es que muchos actores políticos y analistas han percibido como desordenada e incoherente la revolución de los derechos indígenas en Michoacán. Contraria a esta idea, lo que aquí intento mostrar es la coherencia y la racionalidad del desarrollo de este proceso a partir de una perspectiva desde abajo.

Como es ya conocido, la lucha política de la comunidad purépecha de Cherán inició el 15 de abril de 2011 , cuando un grupo de mujeres se enfrentó a talamontes y pistoleros del crimen organizado que durante varios años habían asolado a la comunidad y saqueado sus bosques. Este enfrentamiento derivó en el desconocimiento del gobierno municipal, y un fuerte proceso de organización comunitaria terminó por suplirlo. El resultado de esta insurrección fue un nuevo consenso político fundado en dos pilares: no más partidos políticos y no más policía en Cherán, sí a un gobierno municipal basado en los usos y costumbres y sí a la ronda comunitaria.

Uno de los instrumentos que ha ocupado un lugar central en la lucha de Cherán es el uso contrahegemónico del derecho (Aragón Andrade, 2013 y 2015). De modo que a sus repertorios tradicionales de movilización política la comunidad sumó el uso del derecho estatal a fin de robustecer su lucha para expulsar de ahí a los partidos políticos. A partir de esta demanda Cherán consiguió reformular el derecho a la libre determinación de los pueblos y comunidades indígenas, contenido hasta ese momento como una enunciación abstracta en el artículo $2^{\circ}$ de la constitución federal y en el Convenio 169 de la Organización Internacional del Trabajo (оIт).

Dicha reformulación del derecho a la libre determinación no sólo trascendió la mera vernacularización, sino que además fue imaginado e implementado de forma tal que consiguió modificar desde su base, el municipio, la arquitectura del Estado mexicano. Hasta ese momento se sabía que formalmente las comunidades y pueblos indígenas tenían derecho a la libre determinación, pero el mérito del planteamiento de Cherán fue utilizarlo para transformar la estructura de gobierno del municipio.

Así pues, aprovechando la coyuntura abierta por la recién aprobada reforma al artículo $1^{\circ}$ de la carta magna federal, los purépechas de Cherán invocaron este derecho para solicitar al TEPJF no sólo una elec- ción por usos y costumbres, y así sacar de circulación a los partidos políticos, sino para modificar la forma de gobierno municipal en México heredada desde la Colonia. Como se puede advertir, además de recurrir al derecho estatal y al derecho internacional de los derechos humanos para aplicarlo o, en su caso, adecuarlo a una necesidad concreta, llevaron al límite la implicación de este derecho de los pueblos y comunidades indígenas para promover una transformación mayor en el Estado mexicano y así desbordar sus límites originales.

Esta primera conquista conseguida en 2011 en la Sala Superior del tePJF fue determinante, como se advertirá más adelante, para el posterior desarrollo de los derechos de los pueblos indígenas en Michoacán. Sin embargo, no fue el único momento de contorción del derecho de libre determinación de los pueblos y comunidades indígenas de la entidad. Más recientemente, a mediados de 2015, las autoridades de la comunidad purépecha de Pichátaro acudieron a Cherán a solicitar la ayuda de sus abogados para una lucha que estaban dando desde algún tiempo atrás y que consideraban legal.

A diferencia de Cherán, comunidad que presenta la extraña cualidad, en el contexto michoacano, de ser al mismo tiempo cabecera municipal, la comunidad de Pichátaro tiene una calidad de submunicipalidad, que en Michoacán son conocidas como tenencias. La lucha de Pichátaro incluía también sacar a los partidos políticos de la comunidad, pero la ayuda legal que solicitaban era más bien para pelear una distribución más equitativa de los recursos públicos dentro de su municipio. Su demanda consistía en que la autoridad de Tingambato, municipio al que pertenecen, les permitiera administrar directamente y les entregara de manera proporcional, en términos poblacionales, el presupuesto económico que les correspondía.

Desde su punto de vista, el derecho a la libre determinación amparaba esta posibilidad, y fue de este modo que, en conjunto con ellos, el Colectivo Emancipaciones trabajó en un recurso judicial sometido ante el TEPJF para exigir esta demanda. Se partió del entendido de que el derecho de libre determinación no sólo tiene la dimensión de nombrar autoridades y revitalizar las formas organizativas propias de las comunidades, sino que además implica otras dimensiones que alcanzan esferas como el libre desarrollo económico de las comunidades indígenas.

En este caso nuevamente se desbordó, en mi opinión, el entendimiento tradicional de este derecho, no porque el Convenio 169 de la ort o el artículo $2^{\circ}$ de la constitución federal no lo indicaran así, sino porque esos preceptos, hasta este momento, eran letra 
muerta, y porque la manera en que se echó mano de ellos fue más allá de simplemente efectivizar un derecho. Otra vez se transformó desde su base al Estado mexicano, se dislocó la relación asimétrica entre cabeceras municipales y submunicipalidades, pero sobre todo se asentaron los cimientos para la materialización de un cuarto nivel de gobierno en cuanto nueva expresión de autonomía indígena.

Si bien parto de la idea de que estas reinterpretaciones del derecho a la libre determinación de los pueblos y comunidades indígenas -sobre todo la realizada en 2011 por Cherán- han sido determinantes para comprender la lógica y la revolución de los derechos indígenas, surge una pregunta legítima: ¿cómo es que unos precedentes judiciales pueden abrir tanto el terreno para un proceso así? Incluso antes podría cuestionarse: ¿desde cuándo las comunidades indígenas han logrado victorias tan significativas en el terreno judicial y por qué antes no ocurría? Para responder estos interrogantes es necesario realizar un somero análisis sobre las transformaciones que han sufrido el derecho estatal y sus instituciones en las últimas décadas, como parte del contexto en donde la revolución de los derechos indígenas en Michoacán se ha producido.

\section{Heterogeneidad y esquizofrenia en el derecho estatal mexicano. El pluralismo jurídico de la legalidad estatal}

Una de las deficiencias de algunos análisis críticos del derecho es que parten de la premisa de que el derecho estatal es homogéneo y coherente. Esta paradójica semejanza con las perspectivas positivistas del derecho constituye hoy en día una de las limitaciones más relevantes para comprender los nuevos espacios en los que se construyen la hegemonía y contrahegemonía en el derecho.

Las transformaciones que ha sufrido el derecho estatal mexicano en las últimas décadas han sido de tal dimensión que no se puede simplemente asumir la ficción positivista. Desde la entrada del Estado mexicano al Tratado de Libre Comercio de América del Norte en 1994, hasta la reforma en materia de derechos humanos al artículo $1^{\circ}$ de la constitución federal en 2011 ; desde la hegemonía casi absoluta de los dos poderes políticos (ejecutivo y legislativo) sobre el judicial, hasta la transición a la democracia y el consecuente empoderamiento de los tribunales en México por la judicialización de la política; son sólo algunos factores que han cimbrado la lógica y el funcionamien-

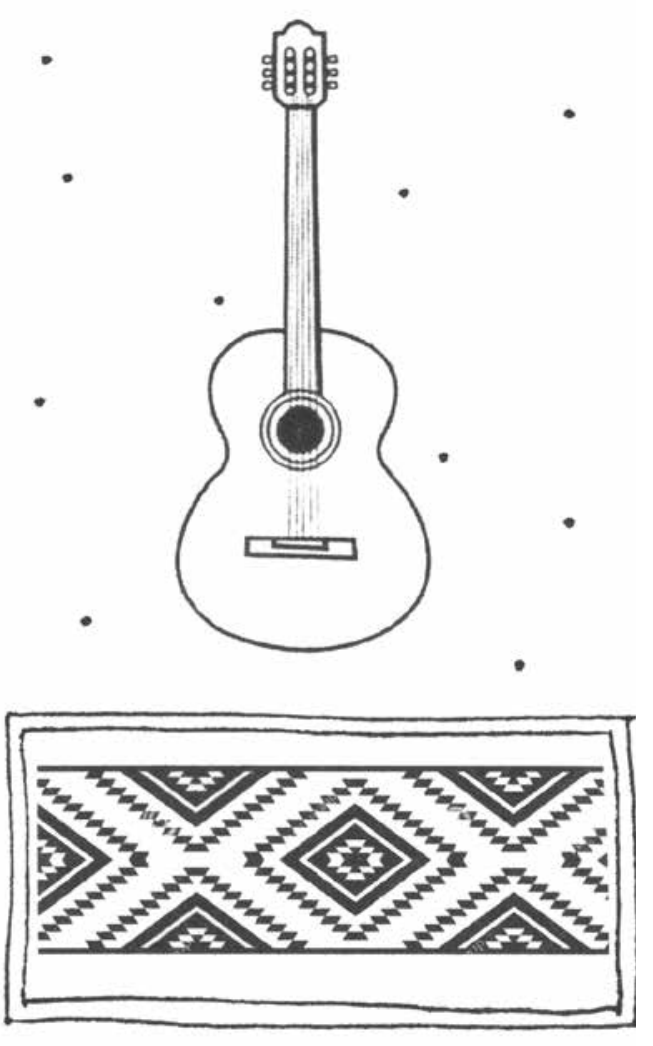

to del derecho estatal mexicano, en sus fuentes de producción normativa y en la relación de sus poderes estatales, alterándolo definitivamente.

Estas grandes transformaciones han implicado entonces un aumento sustantivo en la heterogeneidad del propio derecho estatal que ahora tiene, sociológicamente hablando, distintas fuentes de producción normativa que coexisten a veces de manera armónica, pero en muchos casos de forma conflictiva. Ejemplos comunes de esta situación bien pueden ser los compromisos y nuevas leyes producto de la economía de libre mercado y de su expresión neoextractivista que en ocasiones colisiona con normatividades estatales resultado de episodios en los que el modelo de desarrollo nacional era otro. Un ejemplo prototípico también se puede encontrar en el ámbito de la regulación del derecho laboral, donde una tradición legislativa protectora de los derechos de los trabajadores se enfrenta a nuevas disposiciones jurídicas y políticas sustentadas en el outsourcing y en el despojo de derechos laborales de los trabajadores. La misma situación es fácil hallarla en lo relativo a las disposiciones jurídicas en materia de derechos humanos que el Estado mexicano ha firmado en el nivel internacional, en contraste con la legislación o política interna de seguridad que viola claramente los tratados internacionales que ha suscrito. 
Como se puede advertir, esta heterogeneidad de la legalidad estatal ha incrementado radicalmente lo que he llamado en otro trabajo esquizofrenia en el derecho estatal (Aragón Andrade, 2015). Utilizo esta noción para mostrar situaciones sociojurídicas en los múltiples campos del derecho estatal, que de forma análoga a los síntomas de la patología psiquiátrica, contradicen la percepción de la realidad jurídica de coherencia y homogeneidad que el propio derecho estatal difunde de sí. Vale la pena apuntar que la esquizofrenia en el derecho estatal no sólo se refiere a las antinomias legales, sino a situaciones y lógicas donde las múltiples fuentes normativas del derecho estatal, internamente o entre ellas, generan escenarios de contradicción en el derecho estatal.

No únicamente el incremento de las fuentes de producción normativa del derecho estatal ha agravado la esquizofrenia en éste. El nuevo protagonismo que las altas cortes en México, la Suprema Corte de Justicia de la Nación (scJN) y el TEPJF, han adquirido en años recientes ha sido determinante también en este proceso. ${ }^{2}$ Hasta inicios de la década de los noventa del siglo pasado se consideraba en México al poder judicial como un "poder de tercera", es decir, como un poder completamente subordinado al poder ejecutivo y al legislativo. Esta situación, sin embargo, cambió de manera sustantiva con las crisis de legitimidad de la clase política y de las instituciones electorales en el país. A partir de ese momento el poder de las altas cortes comenzó a crecer, hasta convertirse, en el caso del tePJF, en la principal fuente de legitimidad del poder ejecutivo federal en las últimas dos elecciones.

Aunque estos dos grandes elementos aportan al contexto general de la heterogeneidad y esquizofrenia del derecho estatal, de ninguna manera se limitan a ellos. Se podría hacer un análisis mucho más extenso dependiendo del campo social y del derecho estatal para profundizar este planteamiento, pero no es el objetivo de este artículo. Lo que en todo caso sí quiero advertir es que el incremento de poder de las altas cortes también ha sido desigual entre ellas, no sólo en términos generales sino en las diferentes materias que conocen en sus resoluciones.

Esta situación se puede apreciar muy claramente en la scJn y en el tepJF. Si bien es cierto que ambos órganos judiciales se han fortalecido en las últimas décadas frente a los poderes legislativo y ejecutivo, lo han hecho de manera desigual dependiendo de las materias de los litigios que resuelven. Por ejemplo, Julio Ríos Figueroa (2007) y Arianna Sánchez, Beatriz Magaloni y Eric Magar (2010) coinciden en que después de la reforma judicial de 1994 la scJN se ha fortalecido mucho frente a los otros dos poderes resolviendo conflictos de competencias, entre otros; también se observa que en justiciabilidad de derechos humanos ha tenido una posición más ambigua. Una situación similar se puede advertir en relación con el TEPJF, que es producto de la "transición a la democracia" y del proceso de judicialización de la política, en donde su actuación en los últimos dos procesos electorales para renovar el poder ejecutivo federal quedó totalmente en entredicho, pero en otras materias vinculadas con los derechos humanos ha desarrollado una sorprendente jurisprudencia.

Los derechos de los pueblos indígenas son un buen ejemplo para mostrar esta diferencia. Mientras que la ScJN ha avanzado muy poco en los últimos años -quizás el caso Cherán sea la única resolución relevante que ha emitido-, el TEPJF ha desarrollado toda una jurisprudencia que primero permitió un acceso relativamente efectivo a la justicia del Estado y después luchar por efectivizar su derecho a la libre determinación.

De tal suerte, desde antes de la reforma al artículo $1^{\circ}$ de la constitución federal en 2011 el tepJF había emitido dos criterios jurisprudenciales que permitían a las comunidades indígenas, por un lado, gozar de flexibilidad en los plazos y formalidades legales en la justicia electoral, y por otro, contar con la suplencia total de la queja en los juicios emprendidos por ellos ante el TEPJF. ${ }^{3}$ Esto hizo posible que en un segundo momento la lucha de las comunidades indígenas se trasladara al terreno del derecho a la libre determinación, del cual el caso Cherán fue la piedra de toque.

Precisamente al comenzar a resolver asuntos vinculados con demandas de efectivación del derecho a la libre determinación de las comunidades y pueblos indígenas, el TEPJF se inmiscuyó en un terreno que el poder legislativo y el ejecutivo habían permanecido por completo renuentes a discutir seriamente en México. La incursión del TEPJF en este campo no sólo implicó "aplicar" algo que ya estuviera reconocido, sino generar nuevas situaciones jurídicas que hasta hace poco eran impensables para los estrechos límites de actuación de los tribunales en el país. Empero,

2 Los trabajos de Boaventura de Sousa Santos (2009) y de Rachel Sieder, Line Schjolden y Alan Angell (2011) son excelentes referencias para conocer estos procesos en una dimensión global.

3 El precedente judicial más relevante en donde el TEPJF dio este salto en el acceso efectivo a la justicia del Estado fue el conocido caso Tanetze con número de expediente SUP-JDC 11/2007. 
esta producción de una nueva jurisprudencia no ha sido acompañada por la voluntad de los otros dos poderes del Estado mexicano. El poder legislativo, por ejemplo, no ha hecho grandes adecuaciones a las constituciones y legislaciones secundarias para armonizarlas con las disposiciones de las resoluciones del TEPJF.

Tal escenario ha producido situaciones de esquizofrenia legal donde coexisten realidades jurídicas diferenciadas y hasta encontradas en lo relativo a los ámbitos judicial y legislativo. Esto es lo ocurrido en Michoacán en materia de derechos indígenas. Coexiste la ausencia de voluntad política de los poderes legislativo y ejecutivo de subvertir la situación jurídica de los pueblos y comunidades indígenas de la entidad (ahora reforzada con el temor por el creciente repudio a los partidos políticos), y la lucha de las comunidades que a partir de la resignificación y desbordamiento de su derecho a la libre determinación han encontrado momentáneamente en el ámbito judicial una vía más favorable para conseguir sus demandas.

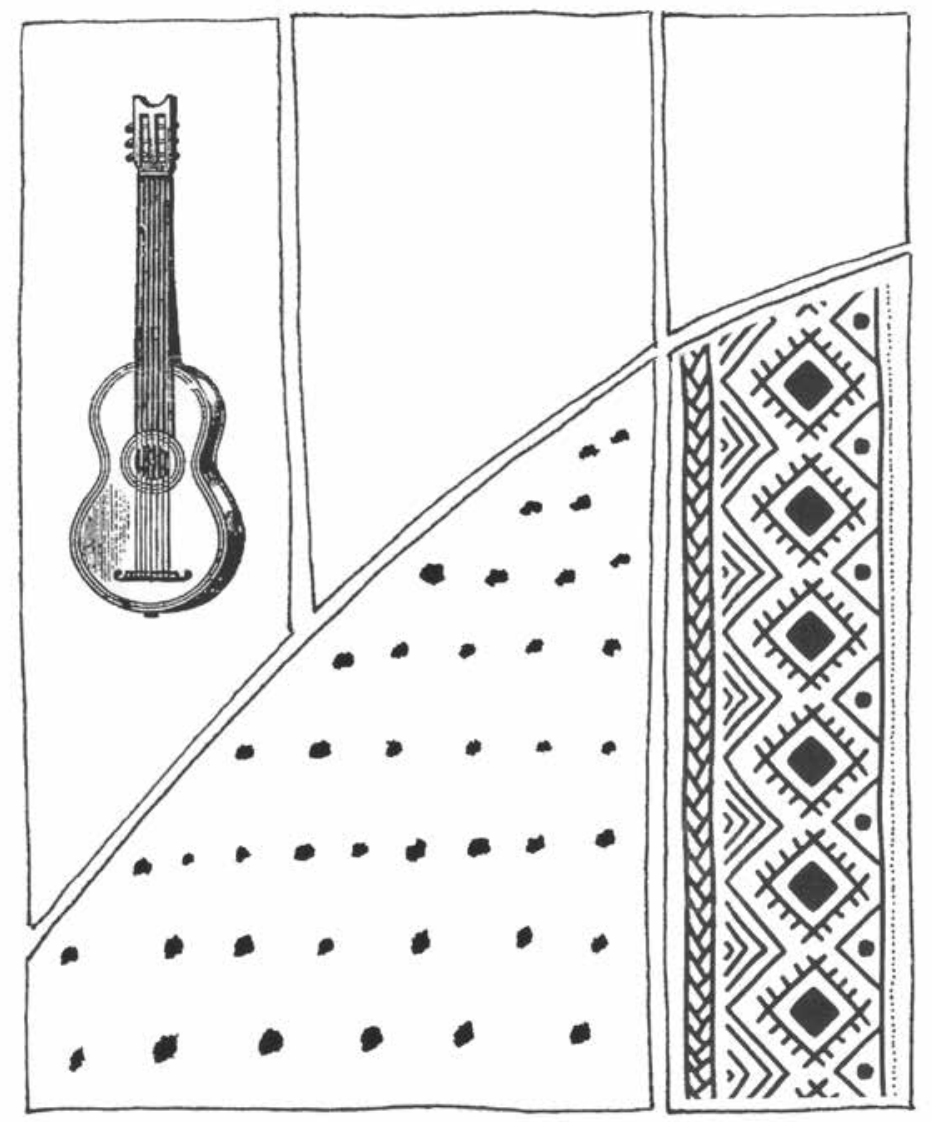

Éste es el marco en el que se ha desarrollado la revolución de los derechos indígenas en Michoacán, y la razón por la que ciertos actores consideran su desarrollo como caótico y sin rumbo claro. Según se puede advertir a esta altura esto no es así, sino que justamente este contexto de heterogeneidad del derecho estatal ha posibilitado nuevos espacios para que las comunidades indígenas disputen, aún de forma desigual, el derecho estatal a otros actores estatales que históricamente se han negado o intentado trivializar sus derechos.

Corresponde ahora, a partir de este marco, explicar con más detalle el itinerario que ha seguido la revolución de los derechos indígenas en Michoacán. A fin de ser coherentes con el planteamiento desarrollado en este apartado lo expondré diferenciando los dos campos relevantes para este proceso de producción normativa del derecho estatal: el judicial y el legislativo.

\section{La revolución de los derechos indígenas en Michoacán en sede judicial}

Como ya señalé, la revolución de los derechos indígenas en Michoacán inició con el triunfo de la comunidad de Cherán en noviembre de 2011, en el Juicio para la Protección de los Derechos Político-Electorales del Ciudadano (JDC) con número SUP-JDC 9167/2011, que les reconoció el derecho a tener una elección y una autoridad municipal conforme a sus usos y costumbres. El logro principal que consiguió Cherán mediante este JDC resuelto por la Sala Superior del TEPJF fue no sólo que se efectuara en Michoacán la primera elección municipal por usos y costumbres, a pesar de no contar con una norma secundaria para tal procedimiento, sino la alteración de la conformación de la autoridad municipal que hasta ese momento había sido exclusivamente la heredada por el Estado mexicano desde la Colonia. ${ }^{4}$

Éstos no fueron, sin embargo, los únicos puntos resolutivos de la sentencia. Otro muy importante consistió en vincular al congreso del estado de Michoacán a legislar y armonizar la constitución local con lo dispuesto por el marco constitucional federal en materia de derechos de los pueblos indígenas, puesto que la Sala Superior advirtió que el congreso de Michoacán

\footnotetext{
4 Justamente este punto marca la diferencia del antecedente oaxaqueño que desde 1977 había reconocido un sistema de elección de autoridades municipales por usos y costumbres. No obstante, este sistema se limitaba al procedimiento de elección y no alteraba la lógica y estructura del ayuntamiento en cuanto autoridad municipal.
} 
había sido omiso por más de diez años en su responsabilidad de armonizar el texto constitucional local, como lo disponían los artículos transitorios de la reforma al artículo $2^{\circ}$. De manera inédita en Michoacán un tribunal ordenó al poder legislativo local legislar ante su inactividad y pasividad.

Precisamente de esta orden y del intento por cumplirla se derivó el segundo precedente judicial de gran trascendencia en materia de derechos de los pueblos indígenas. En efecto, a consecuencia del mandato que le impuso la Sala Superior del TEPJF y en plena efervescencia política por la victoria judicial de Cherán, el congreso de Michoacán decidió aprobar una iniciativa que reformaba principalmente el artículo $3^{\circ}$ de la constitución local $^{5}$ en menos de 30 días después de la emisión de la resolución.

Dicha reforma constitucional, aunque armonizó, en lo general, el texto de la carta magna local con el federal, dejó de lado la inclusión del reciente derecho ganado por Cherán en el TEPJF. De modo que en dicha adecuación al texto constitucional local nada se contempló sobre la posibilidad de que se pudieran realizar elecciones municipales por usos y costumbres, y mucho menos establecer una nueva configuración del gobierno municipal. Tal situación ponía a Cherán en un predicamento sobre lo que ocurriría en el futuro con su nuevo consenso político (Aragón Andrade, 2017), pero además con esta adecuación legislativa el congreso del estado dejaba en vilo el nuevo escenario jurídico creado por el TEPJF. Lo que desde nuestra perspectiva ocurrió con esta reforma constitucional fue una expresión de resistencia por parte del congreso de Michoacán a una situación legal que no estaba dispuesto, políticamente hablando, a reconocer en las leyes.

Por si lo anterior fuera poco, el congreso de Michoacán pasó por alto el derecho a la consulta previa, libre e informada de las comunidades indígenas de la entidad, puesto que el texto que aprobó en un auténtico fast track no fue sometido a ninguna consideración de ellas, incluyendo a Cherán. Ante tal circunstancia, ésta decidió que impugnaría judicialmente la reforma una vez que ejecutara la sentencia del TEPJF y que aquélla fuera publicada. De este modo, a inicios de mayo de 2012 se promovieron dos recursos con el objetivo de revertir la reforma e intentar forzar una consulta a las comunidades para aprobar un nuevo texto constitucional que incluyera la conquista recién lograda por Cherán en el TEPJF.
Los caminos judiciales que escogimos para intentar lograr este objetivo fueron un incidente de ejecución defectuosa de la sentencia de la Sala Superior del TEPJF, que se tramitó ante la misma instancia, y un Juicio de Controversia Constitucional (JCC) promovido ante el Pleno de la scJN. En la primera vía, el incidente de ejecución defectuosa, se argumentó que la sentencia emitida por el TEPJF se había cumplido parcialmente, puesto que, aunque el congreso de Michoacán había legislado y actualizado el marco jurídico constitucional en materia de derechos de los pueblos indígenas, lo había hecho vulnerando los derechos colectivos de éstos. Desafortunadamente para la causa de Cherán este camino no prosperó y el TEPJF dio por cumplida la sentencia que había emitido meses atrás.

El segundo camino se interpuso aprovechando la calidad legal de sede del gobierno municipal de Cherán. El JCC es un procedimiento legal que sólo puede ser promovido por algunos niveles de gobierno y organismos autónomos. Su propósito consiste en resolver conflictos de competencias entre este tipo de actores públicos y tiene como singularidad ser un juicio resuelto por el Pleno de la scJn. Las particularidades de este procedimiento judicial exigieron una serie de adecuaciones de la demanda original de la comunidad. Implicó todo un trabajo de traducción política que ya he analizado a detalle en otro lugar (Aragón Andrade, 2015) para convertir la demanda de Cherán por violación a su derecho humano a la consulta previa, libre e informada, en un conflicto por competencias y atribuciones con el congreso de Michoacán y con el gobernador de la misma entidad.

La fórmula que encontramos para hacer esta adaptación implicó romper con las estrategias jurídicas a las que hasta ese momento habían recurrido algunos ayuntamientos con composición poblacional indígena de acudir a la scJN en defensa de los derechos humanos de sus comunidades indígenas. Lo que se planteó en términos llanos fue que el gobierno municipal de Cherán era producto de una nueva realidad jurídica generada por la resolución del TEPJF; que en ese sentido, como municipio con un gobierno indígena, sus atribuciones, derechos y obligaciones en cuanto autoridad municipal y comunidad indígena no podían disociarse y, por tal motivo, la SCJN debía considerar el derecho a la consulta previa, libre e informada como una atribución más de la autoridad municipal de Cherán frente al congreso y el gobernador de $\mathrm{Mi}$ choacán.

5 Con este cambio en el texto constitucional también se reformó el párrafo tercero del artículo $2^{\circ}$, las fracciones X y XI del artículo 72, el párrafo cuarto del artículo 94, el párrafo tercero del artículo 103, el párrafo tercero del artículo 114 , e incisos y el tercer párrafo del artículo 139. 
Los antecedentes que Cherán tenía a la hora de intentar esta vía procesal no eran para nada alentadores: más de 300 JCC se habían promovido con motivo de la aprobación de la reforma al artículo $2^{\circ}$ en 2001 y todos fueron desechados en su momento. Por esta razón, todo el proceso de este juicio fue cuesta arriba para Cherán. Después de más de dos años que duró el JCC, al cual se le asignó el número 32/2012, el Pleno de la scJn se reunió los días 26, 27 y 29 de mayo de 2014 para discutirlo.

En el primer día de análisis la scJN determinó la procedencia del JCC, además de reconocer al Concejo Mayor de Gobierno Comunal con el mismo nivel jurídico que el de cualquier otro ayuntamiento de México. Por si esto fuera poco, por primera vez en la historia la SCJN se refirió a un municipio como indígena. El segundo día se discutió el fondo del asunto y se concluyó que el congreso de Michoacán y el gobernador habían vulnerado una atribución al gobierno municipal de Cherán al no consultarles la reforma constitucional que habían aprobado y publicado respectivamente. Por último, el tercer día se discutieron los efectos de la sentencia, y, después de una confusa discusión entre los ministros, se determinó que la sentencia favorable para Cherán tendría únicamente efectos particulares.

Este nuevo triunfo judicial producido dos años y medio después de la victoria en el TEPJF implicó el primer precedente judicial en México, y quizás en América Latina, en el que una comunidad indígena logró echar abajo una reforma constitucional por la violación del derecho a la consulta previa, libre e informada. A pesar de lo relevante de este precedente, que incluso fue seleccionado por la scJn como uno de los más importantes en la defensa de los derechos humanos en los 100 años de la constitución de 1917, fuera de lo simbólico, los alcances reales de la resolución de la scJn fueron muy pobres. A diferencia de la resolución del JDC del TEPJF que ganó Cherán, esta sentencia de la scJn dejaba a la comunidad en una situación en la que ganando pudo haber perdido.

El barco pudo salvarse en aquel momento no por la sentencia en sentido riguroso, sino por el uso político que de ella hizo Cherán y por la conjugación de una serie de factores que, como explicaré en el próximo apartado, contribuyeron a que la comunidad lograra los objetivos que habían motivado este segundo juicio.

Así pues, las consecuencias políticas y jurídicas de estos dos litigios no se agotaron en sus efectos estrictos, ni en las situaciones por las que fueron interpuestos. Más allá del proceso político de Cherán, el JDC que ganó en 2011 ha originado toda una nueva jurisprudencia del TEPJF en materia de derecho a la libre determinación y autogobierno de los pueblos y comunidades indígenas de México. Sólo en la judicialización del cambio de gobierno y elecciones municipales por partidos políticos al sistema por usos y costumbres el nivel de repercusión ha impactado ya a otras tres entidades federativas: Guerrero, Ciudad de México y Chiapas.

Para los fines de esta contribución, no obstante, la consecuencia más importante es quizás la influencia que estas victorias judiciales lograron ejercer en otras comunidades indígenas de Michoacán para incorporar el uso contrahegemónico del derecho en sus repertorios de movilización social. De esta forma, muchas comunidades indígenas de Michoacán (y Guerrero, Ciudad de México, Chiapas, Morelos, Puebla, Estado de México, entre otras) se han acercado a Cherán para hablar con sus abogados y pedir consejo y asesoría en distintas problemáticas vinculadas con la violación de su derecho a la libre determinación. Sin embargo, el caso más relevante producto de esta solidaridad de Cherán con la lucha de otras comunidades indígenas de Michoacán ha tenido lugar con la comunidad también purépecha de San Francisco Pichátaro.

Como ya adelanté en el segundo apartado de este trabajo, la lucha de Pichátaro se debió a un problema en la distribución de los recursos económicos entre la cabecera municipal y las submunicipalidades. La relación histórica entre ambas ha sido de subordinación y exclusión que se ha expresado en un exiguo ejercicio de gasto público de los ayuntamientos en las submunicipalidades. Por ejemplo, en Pichátaro, que representa cerca de $35 \%$ de la población total del municipio, la autoridad municipal de Tingambato ejercía -lo cual significaba que ellos decidían en qué- sólo $6 \%$ del total del presupuesto que se le asignaba al municipio. La situación de Pichátaro la comparte la inmensa mayoría de comunidades indígenas en Michoacán, que, a diferencia de Cherán, tienen este estatus de submunicipalidad y se encuentran subordinadas a cabeceras por lo general mestizas.

Lo que resolvimos después de un proceso de estudio con las autoridades de Pichátaro fue seguir su intuición -tal como lo referí en el segundo apartado de esta contribución- de apelar al derecho de libre determinación para pelear que ellos mismos pudieran administrar y decidir sobre los recursos económicos que proporcionalmente les correspondían. De esta forma, promovimos un nuevo JDC ante el TEPJF en el cual se solicitó que la comunidad recibiera el porcentaje de presupuesto total del municipio que le correspondía de acuerdo con el criterio poblacional para que ésta lo administrara directamente. 
Por parecer un litigio de índole administrativa, la argumentación para presentar el JDC ante el TEPJF fue determinante para convencer al tribunal de que se trataba de un juicio en defensa de los derechos políticos de los pueblos y comunidades indígenas. En esta ocasión se argumentó que el derecho a la libre determinación de los pueblos y comunidades indígenas tenía varias dimensiones y que la elección y nombramientos de autoridades era sólo una de ellas. En ese sentido, se planteó que la libre determinación de los pueblos y comunidades pasaba por determinar libremente su desarrollo económico a través de sus propias instituciones y órganos de decisión, y que además el TEPJF debía asegurar su participación efectiva en la vida del Estado mexicano como lo había establecido en su jurisprudencia sobre el derecho al autogobierno indígena.

En mayo de 2016 (después de nueve meses de haber interpuesto la demanda) la Sala Superior del TEPJF resolvió el juicio número SUP-JDC 1865/2016 de manera favorable a la comunidad purépecha de San Francisco Pichátaro para que el ayuntamiento de Tingambato le entregara los recursos y se hiciera la transferencia de derechos y obligaciones que le correspondían. No fue sino hasta octubre de ese mismo año, después de una consulta y de superar una serie de impugnaciones, que la comunidad de Pichátaro logró ejecutar la sentencia y recibir y administrar bajo la nueva figura de un consejo comunal los recursos económicos asignados.

El triunfo de Pichátaro en el TEPJF no fue fácil en absoluto. Más allá de las propias dificultades judiciales de sacar un juicio así, Pichátaro tuvo que enfrentar todo el tiempo un escenario político adverso construido desde la Comisión de Asuntos Indígenas del congreso de Michoacán, que montó una abierta campaña de desprestigio en contra de la lucha de la comunidad e incluso animó hasta que pudo al presidente municipal de Tingambato a desobedecer la resolución del TEPJF.

Esta actitud de nuevo ilustra la esquizofrenia legal ya descrita, en donde autoridades reguladas por el propio derecho estatal, como los diputados y los presidentes municipales, se resisten a cumplir resoluciones de los tribunales y sobre todo muestran una voluntad contraria a reconocer efectivamente el derecho de libre determinación de las comunidades y pueblos indígenas.

El fallo obtenido por Pichátaro ha impulsado a otras comunidades indígenas en Michoacán para promover el mismo juicio y buscar administrar los recursos económicos que las cabeceras municipales les han negado históricamente. Hasta julio de 2017, otras dos comunidades purépechas han alcanzado un recono- cimiento igual que Pichátaro: San Felipe de los $\mathrm{He}$ rreros en el municipio de Charapan y Santa Fe de la Laguna en el municipio de Quiroga. Además de éstas se calcula que 30 comunidades indígenas más en $\mathrm{Mi}$ choacán buscarán ese proceso judicial. Los resultados de este último proceso aún son inciertos, pero de consolidarse el interés de las comunidades podría alterarse el mapa político de Michoacán de manera significativa.

\section{La revolución de los derechos indígenas en Michoacán en el campo legislativo}

Las consecuencias de este activismo judicial de la comunidad de Cherán no se limitaron a ese ámbito, también impactaron en otros campos de producción normativa del derecho estatal, como el legislativo. En efecto, las victorias en el TEPJF y en la scJN se tradujeron, mediante distintas acciones, en transformaciones legislativas en la, hasta ese momento, anacrónica normatividad estatal destinada a los pueblos y comunidades indígenas en Michoacán.

Pues bien, después del resultado del JCC en la SCJN nuevamente fue reformado el texto del mismo artículo constitucional, esta vez para incluir el derecho de los pueblos y comunidades a contar con gobiernos municipales regidos por usos y costumbres. Casi a la par se logró también que se reconocieran y regularan mínimamente las elecciones municipales por el sistema por usos y costumbres en el nuevo código electoral de Michoacán.

Estas últimas dos adecuaciones, sin embargo, no fueron producto de un mandato explícito de la sentencia de la scJn, sino de una nueva movilización política y jurídica de Cherán ahora en el congreso de Michoacán. Como ya advertí, si bien la resolución del JCC 32 / 2012 es histórica para los derechos de los pueblos y comunidades indígenas de México, también es cierto que sus efectos jurídicos concretos fueron muy limitados, pues, aunque se consiguió anular para Cherán la reforma constitucional impugnada, no se dispuso de ninguna medida que tendiera a resarcir el daño sufrido por la violación del derecho a la consulta. Por tal motivo, los efectos jurídicos de la resolución dejaron a Cherán prácticamente en la misma condición legal en el nivel local que la previa a la de 2011.

Ante esta situación, la estrategia política de Cherán consistió en posicionar frente al congreso de Michoacán la versión de que éste estaba obligado a realizar una nueva reforma constitucional y consultársela, aunque esto no lo había dispuesto la resolución de la sCJN. Fortuitamente por aquel momento coincidieron 
los tiempos para que el congreso local armonizara la legislación michoacana en relación con una reforma en el nivel federal que sufrieron buena parte de las instituciones electorales, incluido el antes Instituto Federal Electoral. Este cambio les había significado a los diputados y a sus partidos políticos una larga negociación que estaba llegando a su fin, justo cuando la scJN emitió su resolución a favor del municipio de Cherán. De tal forma, casi tomado su nuevo acuerdo sobre el reacomodo de las instituciones electorales, en el cual otra vez los derechos políticos de los pueblos y comunidades indígenas quedaban fuera, plasmado en un nuevo código electoral, Cherán se encontró con una nueva carta político-jurídica para lograr su objetivo de reformar la constitución y el código electoral para dar certeza al reconocimiento judicial logrado en 2011.

De este modo, se presionó al congreso michoacano amenazándolo con que, si no incluía el reconocimiento de los gobiernos y las elecciones municipales por usos y costumbres, impugnaríamos el nuevo código electoral en su conjunto por no consultarlo a Cherán. No obstante una resistencia inicial de los diputados, al cerciorarse del peligro efectivo que corría el acuerdo que habían alcanzado con tanto trabajo, decidieron ceder a nuestra demanda y así se reformó una vez más el texto del artículo $3^{\circ}$ para reconocer el derecho de las comunidades indígenas de contar con gobiernos municipales por usos y costumbres, así como para escribir en un apretado artículo del nuevo código electoral de Michoacán, el 330, el reconocimiento y la regulación de las elecciones por usos y costumbres en el nivel municipal en la entidad.

Como puede advertirse, lo logrado por la comunidad de Cherán en este episodio fue transformar una victoria judicial en un capital lo suficientemente fuerte para conseguir que el congreso michoacano, muy a pesar de su voluntad, realizara un reconocimiento que se resistió hasta donde pudo. Este procedimiento de transmutación, que llamaré alquimia político-jurídica, además de ser determinante en este episodio, se convirtió en el principal recurso de la estrategia de Cherán para lograr avances en la legislación michoacana en un contexto completamente adverso en este campo de producción normativa del derecho estatal.

Sólo unos meses después y sobre el cierre del periodo de la legislatura LXXII del congreso de Michoacán, se configuró un nuevo escenario donde este trabajo de alquimia político-jurídica fue determinante para conseguir otro avance en los derechos de los pueblos y comunidades indígenas del estado. De una forma parecida al nuevo código electoral, en el congreso se había trabajado durante algún tiempo una ley de mecanismos de participación ciudadana que incluía un apartado sobre la "consulta ciudadana a poblaciones indígenas”. Dicha iniciativa prácticamente había sido consensuada por los diputados, sin consultar a las comunidades indígenas, incluyendo a Cherán. Cuando las autoridades de la comunidad se enteraron de la existencia de esta iniciativa actuaron de manera inmediata y se acudió al congreso michoacano para exigir a los diputados una consulta de esa ley. El elemento blandido en este episodio fue, de nuevo, la amenaza de que de no producirse la consulta exigida se impugnaría la ley en su conjunto.

Frente a esta situación los diputados ofrecieron a los representantes de Cherán que les presentaran una propuesta de adecuaciones al texto que estaban por aprobar, con la promesa de que harían los cambios sugeridos en los días inmediatos a la aprobación de la ley. La garantía que la comunidad tenía de que estos cambios se realizaran fue que quedó intacto su derecho de acudir a los tribunales por la violación del derecho a la consulta previa, libre e informada. Fue así que la comunidad de Cherán consiguió reescribir los artículos 73, 74, 75 y 76 correspondientes al derecho a la consulta. En el rediseño de la reglamentación Cherán incluyó no sólo los estándares más altos de este derecho, sino que trascendió varios de ellos. Por ejemplo, en Michoacán la consulta, gracias a esta ley, tiene efectos vinculantes; todo el proceso de consulta se debe realizar en coordinación, de inicio a fin, entre la autoridad electoral y la comunidad interesada; los aspectos no previstos en la regulación deben ser suplidos por los estándares internacionales más favorables para las comunidades y pueblos indígenas de la entidad; entre otros.

Una última experiencia de esta alquimia políticojurídica movilizada por Cherán en el campo legislativo fue la iniciativa de reforma al artículo 115 de la constitución federal presentada en el Senado de la República en abril de 2016, para lo cual la comunidad utilizó su capital político y jurídico acumulado durante cinco años de movimiento.

La decisión de trabajar en la presentación de una iniciativa de esta naturaleza se debió a la continua cerrazón del congreso estatal a reconocer plenamente el derecho de libre determinación de los pueblos y comunidades indígenas. Pese a los avances conseguidos por la comunidad en estos años, los diputados locales se han negado a realizar una reforma lo suficientemente amplia para armonizar las diferentes leyes que regulan el gobierno y la administración municipal, entre ellas la ley orgánica municipal.

La ley orgánica municipal reviste una singular importancia para Cherán; ya se ha conseguido un 
reconocimiento constitucional del derecho de las comunidades a tener gobiernos municipales indígenas, pero muchos asuntos cotidianos de la administración municipal se regulan en esta legislación secundaria que ha permanecido intacta a pesar de los avances consignados. Esta falta de armonización legal ha permitido a muchos funcionarios del gobierno de la entidad negarse a reconocer algunos órganos del gobierno municipal de Cherán alegando su inexistencia en la legislación secundaria.

Frente a la falta de voluntad de la actual legislatura del congreso de Michoacán de modificar la ley orgánica municipal y en general cualquier ley que involucre derechos de los pueblos y comunidades indígenas de la entidad, los representantes de Cherán y el Colectivo Emancipaciones decidimos subir la apuesta y acudir a una instancia federal del poder legislativo, el Senado de la República, donde había una mayor apertura a nuestro planteamiento. Este cambio de instancia implicó asimismo un cambio en el cuerpo legal a modificar. Como la ley orgánica municipal es una legislación local del ámbito exclusivo del congreso de Michoacán, decidimos subir también la apuesta normativa al texto de la constitución federal encargado de regular a los municipios en todo el Estado mexicano. La idea fue intentar conseguir modificar primero el artículo 115 de la constitución federal, para después con esa plataforma presionar a la legislatura local para cambiar ahora sí la ley orgánica municipal.

Aunque el día de la presentación de la iniciativa en el Senado tuvimos señales alentadoras sobre este intento de conquistar un nuevo enclave en la legislación (casi todos los senadores de Michoacán hicieron suya la propuesta de Cherán y se sumaron a ésta senadores de Guerrero, Oaxaca y Chiapas), las semanas nos fueron desalentando en la medida en que poco a poco la iniciativa presentada se fue perdiendo en el olvido del trabajo legislativo del Senado de la República.

\section{Reflexiones finales}

La revolución de los derechos indígenas en Michoacán amerita esa denominación sobre todo por los elementos aquí estudiados. Es una revolución de los derechos en el sentido de que se trata de subversiones del discurso tradicional de los derechos humanos por actores subalternos, que en condiciones de gran desigualdad lograron usar el derecho estatal para generar alternativas con las cuales enfrentar viejos y nuevos desafíos. Se trata también de una revolución de los derechos porque en tan sólo seis años los nuevos movimientos indígenas de Michoacán consiguieron transformar radicalmente su precaria condición jurídica en la entidad, que, si bien en cierto modo no deja de ser frágil, se ha convertido en una de las más avanzadas en el contexto nacional y latinoamericano. Finalmente se trata de una revolución de los derechos porque, aunque es un proceso abierto, tiene el potencial político para constituirse en una nueva etapa de avances jurídicos para los pueblos y comunidades indígenas de México posterior a la era del reconocimiento jurídico vía legislativa que dominó la última década del siglo pasado y la primera de éste. La apropiación de la vía judicial generada por Cherán por municipios, comunidades y barrios indígenas de Guerrero, Ciudad de México y Chiapas es sólo un síntoma que anuncia esta posibilidad.

\section{Cuadro 1}

Hitos de la revolución de los derechos indígenas en Michoacán

Campo judicial

2011 Juicio para la Protección de los Derechos Político-Electorales del Ciudadano SUP-JDC 9167/2011 Cherán vs. Instituto Electoral de Michoacán

2014 Juicio de Controversia Constitucional 32/2012 Cherán vs. Congreso del Estado y Gobernador de Michoacán

2015

2016
Juicio para la Protección de los Derechos Político-Electorales del Ciudadano SUP-JDC 1865/2016 Pichátaro vs. Tingambato
Campo legislativo

Reforma al artículo $3^{\circ}$ y fracciones del $2^{\circ}, 72,94,103$, 114 y 139 de la constitución de Michoacán

1. Reforma al artículo $3^{\circ}$ de la constitución de Michoacán 2. Artículo 330 del Código Electoral de Michoacán

Capítulo de relativo a la "Consulta ciudadana a comunidades indígenas" de la Ley de Mecanismos de Participación Ciudadana

Presentación parte de Cherán de la iniciativa de reforma al artículo 115 de la constitución federal en el Senado de la República 
Como se puede advertir, la circunstancia michoacana de la revolución de los derechos indígenas se produjo en un contexto de creciente heterogeneidad y esquizofrenia en el derecho estatal mexicano y sus instituciones. Por esta razón, aunque el nuevo papel que han jugado las altas cortes en México ha sido vital para hacer frente a la cerrazón y falta de voluntad política de los gobernadores y legisladores michoacanos para reconocer los derechos de las comunidades indígenas, el mérito principal de este proceso no puede ser más que las comunidades referidas que han conseguido aprovechar este nuevo espacio de la contrahegemonía jurídica para desbordar la lectura tradicional de sus derechos, efectivizarlos y lograr impulsar transformaciones (a partir de diferentes acciones como la alquimia político-jurídica) a la base política del Estado mexicano.

A pesar de las victorias alcanzadas en tan sólo seis años, el contexto político adverso y la ambigüedad del campo de la legalidad estatal son un claro reflejo de la fragilidad en la que la revolución de los derechos indígenas de Michoacán se ha producido $\mathrm{y}$, por lo tanto, de su potencial carácter efímero. Esta situación, no obstante, difícilmente podría ser de otra manera en un esquema en que la legalidad estatal es utilizada para transformar condiciones de injusticia y exclusión que padecen las comunidades indígenas. El uso contrahegemónico del derecho estatal se encuentra atrapado siempre en este punto.

\section{Fuentes}

Aragón Andrade, Orlando

2013 "El derecho en insurrección. El uso contrahegemónico en el movimiento purépecha de Cherán", en Revista de Estudos e Pesquisas sobre as Americas, vol. 7, núm. 2, pp. 37-69.

Aragón Andrade, OrLANDO

2015 "El derecho después de la insurrección. Cherán y el uso contra-hegemónico del derecho en la Suprema Corte de Justicia de México", en Sortuz: Oñati Journal of Emergent Socio-Legal Studies, vol. 7, núm. 2, pp. 71-87.

Aragón Andrade, Orlando

2017 "Transformando el constitucionalismo transformador: lecciones desde la experiencia polí- tico-jurídica de Cherán, México”, en Abya Yala: Revista sobre Acesso à Justiça e Direitos nas Américas, vol. 1, núm. 2, pp. 130-149.

ARAgón AndRade, ORLANDO

Y GLADYS MONTERO TAPIA

2008 "Los pueblos indígenas ante la constitución de Michoacán”, en Orlando Aragón Andrade (coord.), Los derechos de los pueblos indígenas en México. Un panorama, Universidad Michoacana de San Nicolás de Hidalgo, Morelia, pp. 205-220

Epp, Charles R.

2013 La revolución de los derechos. Abogados, activistas y cortes supremas en perspectiva comparada, Siglo XXI, Buenos Aires.

Merry, Sally Engle

2010 Derechos humanos y violencia de género: el derecho internacional en el mundo de la justicia local, Siglo del Hombre Editores/Universidad de los Andes, Bogotá.

RAJAGOPAL, BALAKRISHNAN

2005 El derecho internacional desde abajo. El desarrollo, los movimientos sociales y la resistencia en el tercer mundo, Instituto Latinoamericano de Servicios Legales Alternativos, Bogotá.

Ríos Figueroa, Julio

2007 "Fragmentation of Power and the Emergence of an Effective Judiciary in Mexico, 1994-2002", en Latin American Politics and Society, vol. 49, núm. 1, pp. 31-57.

Sánchez, Arianna, Beatriz Magaloni

Y ERIC MAGAR

2010 "Legalistas vs. interpretativistas: la Suprema Corte y la transición democrática en México", en Gretchen Helmke y Julio Ríos Figueroa (coords.), Tribunales constitucionales en América Latina, Suprema Corte de Justicia de la Nación, México, pp. 317-379.

Santos, Boaventura de Sousa

2009 "Sociología crítica de la justicia", en Sociología jurídica crítica. Para un nuevo sentido común en el derecho, Trotta, Madrid, pp. 81-128.

ScotT, JAMES

1998 Seeing like a State. How Certain Schemes to Improve the Human Condition Have Failed, Yale University Press, New Haven.

Sieder, Rachel, Line SchJolden

y Alan ANGEll

2011 La judicialización de la política en América Latina, Centro de Investigaciones y Estudios Superiores en Antropología Social/Universidad Externado de Colombia, México.

Ventura Patiño, María del CARMen

2010 Volver a la comunidad. Derechos indígenas y procesos autonómicos en Michoacán, El Colegio de Michoacán, Zamora. 